\title{
RECURSOS HÍDRICOS: POLUIÇÃO, ESCASSEZ, QUALIDADE MICROBIOLÓGICA E QUÍMICA DA ÁGUA
}

\author{
Fabiola de Azevedo Mello ${ }^{1}$, Andreia de Menezes Olivo². \\ ${ }^{1}$ Universidade do Oeste Paulista - UNOESTE, Pós-Graduação Lato Sensu em Microbiologia, Presidente Prudente, SP. E- \\ mail: fabiola-azevedo@hotmail.com
}

\section{RESUMO}

A diminuição da água potável no Brasil é uma realidade preocupante, pois o indivíduo a utiliza com o intuito de suprir suas necessidades pessoais, produção industrial, agrícola e comercial. 0 resultado da poluição proveniente das grandes cidades e do aumento demográfico é conhecido como poluição química e acaba sendo considerada a mais danosa, pois é causada pela presença de substâncias nocivas e tóxicas ao homem e também ao meio ambiente. Sendo assim, as diferentes maneiras de poluir, acompanhadas por atividades antropogênicas, prejudicam a vida humana e também da natureza, com isso, seu equilíbrio e preservação tornam-se fundamentais para a sobrevivência da humanidade. O presente trabalho teve como objetivo abordar a importância do elemento água e os fatores relacionados à poluição hídrica e qualidade microbiológica e química das águas. Pretende ainda, expor os impactos que sua escassez poderá provocar em todo o planeta e quais serão os reflexos da ação antropogênica.

Palavras-chave: Recurso hídrico, contaminação, poluição, qualidade microbiológica e ação antropogênica.

\section{WATER RESOURCES: POLLUTION, SHORTAGE, MICROBIOLOGICAL QUALITY AND CHEMISTRY OF WATER}

\begin{abstract}
The decrease in drinking water in Brazil is a worrying reality for the individual to use in order to meet their personal needs, industrial, agricultural and commercial. The result of pollution from large cities and population growth is known as chemical pollution and ends up being considered the most harmful, because it is caused by the presence of harmful and toxic to humans and also the environment. Thus, the different ways to pollute, accompanied by human activities, harmful to human life and the nature, therefore, their balance and preservation become crucial to the survival of humanity. This study aimed to address the importance of the water element and the factors related to water pollution and microbiological quality and water chemistry. It also intends to expose the impacts that their scarcity may cause around the world and what are the consequences of anthropogenic action.
\end{abstract}

Keywords: water resource, contamination, pollution, microbiological quality and anthropogenic action. 


\section{INTRODUÇÃO}

A água ocupa quase três quartos de toda a superfície da Terra, sendo um dos principais recursos que propiciam a vida. Aproximadamente $97,13 \%$ de toda água mundial é salgada e apenas $2,87 \%$ é doce, onde $78,05 \%$ concentram-se em geleiras; $21,32 \%$ em subsolos e $0,63 \%$ na atmosfera, rios e lagos (BENEDETTI, 2013).

A utilização desse recurso pelo homem visa suprir suas necessidades pessoais, produção agrícola, industrial e comércio, adquirindo um alto valor econômico. Mas quando seu uso é realizado de maneira incorreta, provoca alterações na qualidade de vida dos indivíduos, dos recursos hídricos e consequentemente, em seus diversos usos (DE SOUZA et al., 2014).

Cerca de $80 \%$ de toda água doce presente no Brasil encontra-se na Amazônia, onde mora apenas $5 \%$ de toda a população brasileira e os $20 \%$ que restam, abastecem o restante da população do país (BENEDETTI, 2013). De acordo com Do Carmo (2014) 20\% do consumo de água no país destina-se as atividades industriais e $62 \%$ a produção agrícola. Outro estudo demonstra que quase $40 \%$ de toda água utilizada em residências são para fins não potáveis (DUARTE et al., 2015).

A crise hídrica mais recente no Brasil ocorreu na cidade de São Paulo no ano de 2014. O Sistema Cantareira apresentou grande baixa em seu volume e consequentemente, os moradores tiveram que alterar seus hábitos diários em relação ao uso da água. A Organização das Nações Unidas (ONU), em 20 de março de 2015, apresentou um relatório intitulado "Água para um mundo sustentável", cujo intuito foi fazer com que todos cuidassem desse recurso natural, que é fundamental, além de alertarem o declíneo de 40\% da água potável até 2030 (ONU, 2015).

Esse estudo tem como objetivo abordar a fundamental importância da água e os fatores relacionados à poluição hídrica e a qualidade microbiológica e química das águas. Pretende ainda, expor os impactos que sua escassez poderá provocar em todo o planeta e quais serão os reflexos da ação antropogênica.

\section{POLUIÇÃO HÍDRICA}

Ultimamente, o tema água tem-se feito presente nas agências políticas da Europa e também nas internacionais, sendo a principal preocupação ambiental dos indivíduos. A dificuldade em obter esse recurso nas grandes cidades e o alto custo cobrado para se ter acesso a ela nos remete a necessidade de conservá-la e utilizá-la com consciência.

O esgoto doméstico ou indústrial, também chamado de efluente, é um termo usado para águas que perderam suas características naturais, ou seja, aquelas que foram alteradas. São compostas por água doméstica, excretas dos seres humanos, água dos comércios e também das indústrias. O Instituto Brasileiro de Geografia e Estatítica (IBGE) afirmou que em 2010 47,8\% dos municípios do Brasil não apresentavam rede de esgoto (PEREIRA et al,. 2015).

São consideradas como as maiores fontes poluidoras no país as agroindústrias, devido a enorme quantidade de componentes ricos em matéria orgânica, nutrientes (como fósforo e nitrogênio), graxa e óleos provenientes de todas as atividades relacionadas nesses locais (MEES et al., 2009).

Com o intuito de tratar a água utilizada (contaminada), tanto em redes domésticas, quanto em industriais, criou-se as estações de tratamento de efluentes, conhecidas como ETE. De acordo com a Resolução 357, de março de 2005, do CONAMA (Conselho Nacional do Meio Ambiente) em seu art. $2^{\circ}$, inciso $\mathrm{XV}$, classifica esse sistema como "corpo hídrico superficial que recebe o lançamento de um efluente" (BRASIL, 2005).

As ETEs tem como função tratar o esgoto, com o intuito de reintegrá-los na natureza. Esse tipo de tratamento inclui diversas operações que removem as substâncias indesejáveis, ou transforma-las em outras, com o intuito de torná-las menos perigosas ao meio ambiente. 
Inúmeras epidemias e doenças no trato gastrointestinal apresentam como fonte de infecção a água poluída e o esgoto é conhecido por conter diferentes microrganismos como bactérias do grupo coliforme, vírus e vermes. Doenças vinculadas por esse recurso são causadas por patógenos de etiologia entérica, ou seja, provenientes do intestino de humanos ou animais, transmitidos por via fecal-oral (DA SILVA et al., 2014).

\section{Qualidade microbiológica da água para o consumo humano}

Sabe-se que a água é um recurso fundamental para que todos os seres vivos possam sobreviver, mas para que os indivíduos possam consumi-la, esta deve estar limpa, livre de contaminação e patógenos que causam danos à saúde. De acordo com Muller (2014), estima-se que $80 \%$ de todas as doenças que tem origem hídrica são causadas devido a contaminação desse recurso.

Antes do século XIX a qualidade da água associava-se apenas aos aspectos estéticos e sensoriais (odor, gosto e cor). A contaminação das águas dos rios, reservatórios e lagos deu-se através da crescente expansão demográfica e industrial ocorrida ao longo dos anos. Com todas as alterações, os recursos hídricos passaram a trazer risco à saúde da população devido a má qualidade, sendo um veículo transmissor de diversos agentes químicos e biológicos (QUEIROZ et al., 2012).

Ainda de acordo com Queiroz (2012), este afirma que a potabilidade desse recurso define-se através de diversos parâmetros e padrões estabelecidos por legislações sanitárias e normatizações. A portaria $n^{\circ} 518$, de 25 de março de 2004, estabelecida pelo Ministério da Saúde, preconiza todos os procedimentos e responsabilidades que devem ser empregados na qualidade da água para o consumo humano, além de seu padrão de potabilidade .

Os agentes biológicos encontrados em águas contaminadas são do grupo coliformes totais, que incluem bacilos gram-negativos pertencentes a família Enterobacteriaecea, não esporulados, fermentadores de lactose com produção de gás quando incubados a uma temperatura de $37^{\circ} \mathrm{C}$ de 1 a 2 dias (24-48 horas). Destacam-se como as principais bactérias desse grupo os gêneros Escherichia, Citrobacter, Enterobacter e Klebsiella.

Bactérias classificadas como coliformes termotolerantes incluem-se no grupo dos totais, mas apresentam a capacidade de continuar a fermentação da lactose nas temperatiras de $44-45^{\circ} \mathrm{C}$ em 24 horas, com formação de gás. A bactéria Escherichia coli é um exemplo desse grupo, sendo utilizada como indicador de contaminação fecal, já que é um microrganismo presente na microbiota intestinal dos animais. Em alguns casos, essa bactéria associa-se a infecções causadas no intestino de crianças e/ou adultos, conhecida como E. coli diarreiogênica (SCHUROFF et al., 2014).

O objetivo de monitorar a qualidade microbiológica da água é garantir o padrão de potabilidade para o consumo humano. Seus padrões de qualidade no Brasil são estabelecidos de acordo com a Portaria n$^{\circ} 2914$ de dezembro de 2011, do Ministério da Saúde (MS), que define que quando o recurso hídrico é utilizado para o consumo humano o mesmo não deve apresentar coliformes totais e termotolerantes (BRASIL, 2012).

A finalidade que a água será utilizada requer diferentes características microbiológicas quantitativas, tais como físico-químicas e bioquímicas (potencial hidrogeniônico- $\mathrm{pH}$; temperatura; condutividade; turbidez; demanda bioquímica de oxigênio- DBO; demanda química de oxigênioDQO) e qualitativas. A Resolução do Conselho Nacional do Meio Ambiente (CONAMA) n³57/2005 classifica os recursos hídricos de todo o país em águas doces, salobras e salinas, em relação a concentração de sais (BRASIL, 2005).

Com todas as alterações decorrentes ao longo dos anos, a água subterrânea passou a ser uma grande fonte de abastecimento, já que os indivíduos passaram a se preocupar com a 
poluição, proliferação desenfreada de doenças, além dos custos elevados para a obtenção desse recurso.

De acordo com Dos Santos et al(2015) até meados dos anos 70, os recursos subterrâneos não apresentavam contaminação porque as camadas de solo e rochas filtravam as impurezas presentes na água. Mas com o passar do tempo, foram encontrados contaminantes devido a presença de esgotos (industriais ou domésticos), resíduos oriundos de postos de combustíveis e atividades agropecuárias. A contaminação pode ocorrer também em seu ponto de origem, em sua distribuição e reservatórios (empresas ou domicílios) que não vedam corretamente as cisternas e caixas d'água ou que não a desinfetam periodicamente e regularmente.

A transmissão de enfermidades através da água se dá pelo tratamento inadequado desse recurso. A presença de fezes humanas e/ou animais traz consigo microrganismos patogênicos (BRASIL, 2006). As principais doenças causadas por eles são: cólera, esquistossomose, disenteria, giardíase, oxiurose e ascaridíase (DOS SANTOS et al., 2015).

A introdução dos patógenos no indivíduo se dá por via cutânea ou através da ingestão de água contaminada por meio de recreações e preparo de alimentos (YAMAGUCHI, 2013). Em países subdesenvolvidos as doenças diarreicas causadas pela contaminação hídrica são frequentes em decorrência das precárias condições de saneamento básico, além da má qualidade desse recurso. A cólera, hepatite $A$, amebíase e giardíase foram responsáveis por inúmeros surtos epidemiológicos e altas taxas de mortalidade em crianças, em decorrência do consumo de água contaminada (JAWETZ, 1998).

Para que o recurso esteja sem microrganismos patogênicos, o mesmo deve passar por um processo conhecido como desinfecção, sendo a cloraçao o método mais conhecido (YAMAGUCHI, 2013).

\section{ESCASSEZ DE ÁGUA: CONSUMO X CRESCIMENTO DEMOGRÁFICO}

A relação existente entre os indivíduos e o meio ambiente é marcada pela relação entre o volume da população e a disponibilidade dos recursos naturais presentes no ambiente (DO CARMO, 2014). Em diversas regiões do Brasil existem situações de escassez, que ocorrem devido as condições naturais, pelo mau uso da água, poluição e contaminação dos recursos hídricos, crescimento demográfico, entre outros fatores.

O Brasil é considerado um país extenso, com 8,5 milhões de $\mathrm{Km}^{2}$ e que no ano de 2010 apresentou uma população de 190,7 milhões de pessoas. Composto por 5.565 municípios e com mais de 21 cidades metropolitanas (IBGE, 2010). Nesse contexto, a água acaba sendo uma preocupação devido ao intenso e rápido aumento do uso desse recurso.

Mesmo diante de inúmeros acontecimentos e inovações ao longo dos anos, ainda existem em nosso país indivíduos que moram em áreas urbanas e que não tem acesso a água potável, ou que não têm acesso à ela o dia inteiro (CARMO et al., 2013).

Sabe-se que a agricultura é o setor que consome mais água, com um consumo de aproximadamente 70\% (LIRA, 2015). Quando aliada ao crescimento populacional, a necessidade de produzir alimentos também cresce, sendo necessária maior quantidade desse recurso.

O aumento do consumo hídrico não ocorre somente devido ao crescimento demográfico, mas também pela vontade dos indivíduos em consumir alimentos mais saborosos. Com o aumento das práticas de irrigação, cujo intuito é intensificar a oferta dos produtos agrícolas, as áreas irrigadas também crescem. Em áreas de clima temperado, as chuvas caem periodicamente e fica difícil perceber o quanto de água acaba sendo consumido nesse setor, mas em regiões secas, esse gasto é nítido, chegando a quase $80 \%$ de toda água disponível (LIRA et al., 2015).

O fenômeno de estiagem tem ocorrido com grande frequencia em diversas regiões do Brasil, causando deficiência hídrica, além de prejuízos na agricultura, criação de suínos, bovinos e aves, comprometendo também o abastecimento da população em algumas regiões. Áreas que 
apresentam alto volume de precipitação também há escassez de água, prejudicando a produção agropecuária, já que somente algumas propriedades armazenam água em sisternas de irrigação (FERREIRA, 2014).

\section{CONSIDERAÇÕES FINAIS}

As diversas maneiras de poluir, sendo elas direta ou indireta, são acompanhadas por atividades antropogênicas que prejudicam a vida do homem de diferentes maneiras e intensidades. A preocupação com a diminuição da qualidade da água devido há diversos fatores traz reflexos aos indivíduos que devem unir-se para encontrar soluções.

A água é indispensável para todas as populações de seres humanos, mas vem sendo utilizada em excesso e frequentemente poluída, tornando-se escassa ou imprópria para o consumo em diversas regiões do mundo, trazendo consequências e diversos prejuízos aos indivíduos e a todos os seres vivos. Considera-se ainda que sua má qualidade (poluída ou contaminada) faz com que se torne fonte de diversas doenças e problemas de saúde.

Desta forma, é necessário dar mais atenção a esse grande problema, alertando os indivíduos sobre a necessidade de adotar atitudes e medidas que possam garantir suas características químicas e microbiológicas, com o intuito de alcançar as condições sanitárias adequadas da água de consumo.

As consequências geradas pela poluição química desse recurso sobre a população deve ser avaliada e considerada. Os avanços dos recursos tecnológicos são necessários para que haja o crescimento e desenvolvimento econômico no país, mas devem ser vistoriados com o intuito de promover a manutenção do meio ambiente à favor dos seres humanos. Sendo este, responsável por interagir, diretamente, na saúde da população e com isso, seu equilíbrio e preservação tornam-se fundamentais para nossa sobrevivência.

\section{CONFLITO DE INTERESSE}

Os autores declaram não haver qualquer potencial de conflito de interesse que possa interferir na imparcialidade deste trabalho científico.

\section{REFERÊNCIAS}

BENEDETTI, E. Água- Fonte da vida- Considerações. Veterinária Notícias, Uberlândia, v. 18, n. 1, p. 1-5, jan./jun. 2013.

BRASIL. Conselho Nacional do Meio Ambiente. Resolução n. 357, de 17 Março de 2005. Disponível em: < http://www.mma.gov.br/port/conama/res/res05/res35705.pdf>. Acesso em: 13 de abr. 2015.

BRASIL. Ministério do Meio Ambiente. Resolução no 357 de 17 de Março de 2005. Disponível em: < http://www.mma.gov.br/port/conama/res/res05/res35705.pdf>. Acesso em: 05 de mar. 2015.

BRASIL. Ministério da Saúde. Portaria n. 2914 de 12 de Dezembro de 2011. Disponível em: < http://bvsms.saude.gov.br/bvs/saudelegis/gm/2011/prt2914_12_12_2011.html>. Acesso em: 05 de mar. 2015.

CARMO, R. L et al. População e consumo urbano de água no Brasil: interfaces e desafios. Simpósio Brasileiro de Recursos Hídricos. 2013.

COSTA, C. M. S. et al. Controle da Poluição da Água em Maceió. Cadernos de Graduação, Maceió, v. 1, n.1, p. 41-50, mai. 2014. 
DA SILVA, C. C. et al. Análises do Perfil Bacteriológico das Águas do Ribeirão das Antas, no Município de Cambuí-MG, Como Indicador de Saúde e Impacto Ambiental. Revista Agrogeoambiental, 2014.

DO CARMO, R. L.; DE SAMPAIO DAGNINO, R.; JOHANSEN, I. C. Transição demográfica e transição do consumo urbano de água no Brasil. Revista Brasileira de Estudos de População, Rio de Janeiro, v. 31, n. 1, p. 169-190, jan./jun. 2014.

DOS SANTOS, D. J. et al. Análise físico-química e microbiológica da água de poços superficiais, caixas d'água e do sistema de tratamento, em residências no município de Nova Xavantina-MT. Revista Eletrônica Interdisciplinar, v. 1, n. 13, p. 31-6. 2015.

DUARTE, G. W. et al. Aproveitamento de Água Pluvial para Fins não Potáveis: estudo de caso na jardinagem. Revista Ciência \& Cidadania, v. 1, n. 1, p. 8-18. 2015.

FERREIRA, M. G. Análise da variabilidade da precipitação e da estiagem no município de Erechim e Região Norte do Rio Grande do Sul. 2014. 45 f. Monografia (Bacharel em Geografia). Universidade Federal do Rio Grande do Sul, Rio Grande do Sul- RS.

JAWETZ M. J, M. J. L.; ADELBERG E. A. Microbiologia Médica. 20. ed. Rio de Janeiro: Guanabara Koogan, 1998.

LIRA, R. M. et al. A utilização de águas de qualidade inferior na agricultura irrigada| The use of lower quality water in irrigated agriculture. Revista Geama, Recife, v. 2, n. 2, p. 95-128, dez. 2015.

MEES, J. B. R. et al. Removal of organic matter and nutrients from slaughterhouse wastewater by using Eichhornia crassipes and evaluation of the generated biomass composting. Revista Engenharia Agrícola, v. 29, n. 3, p. 466-73, jun./set. 2009. https://doi.org/10.1590/S0100$\underline{69162009000300013}$

MULLER, L. R. PARUSSOLO, L. Qualidade microbiológica da água utilizada para consumo em escolas municipais de Mamborê, Paraná. SaBios-Revista de Saúde e Biologia, v. 9, n. 1, p. 95-99, jan./abr. 2014.

ONU. Até 2030 planeta pode enfrentar déficit de água de até 40\%, alerta relatório da ONU. Disponível em: <http://www.unesco.org/new/pt/brasilia/about-this-office/singleview/news/urgent_need_to_manage_water_more_sustainably_says_un_report/\#.V0XIOHruPEE> Acesso: 03 mar. 2015.

PEREIRA, A.A.S. et al. Avaliação da qualidade da água do Ribeirão São João, em Campo Belo Minas Gerais, sob interferência do efluente tratado do abate de bovinos e suínos. Natureza on line, Ribeirão São João, p. 101-105, nov./abr. 2015.

QUEIROZ, A. C. et al. Programa Nacional de Vigilância em Saúde Ambiental Relacionada à Qualidade da Água para Consumo Humano (Vigiagua): lacunas entre a formulação do programa e sua implantação na instância municipal. Saúde e Sociedade, v. 21, n. 2, p. 465-478. 2012. https://doi.org/10.1590/S0104-12902012000200019 
SCHUROFF, P. A. et al. Qualidade microbiológica da água do Lago Igapó de Londrina-PR e caracterização genotípica de fatores de virulência associados a Escherichia coli enteropatogênica (EPEC) e E. coli produtora de toxina Shiga (STEC). Semina: Ciências Biológicas e da Saúde, Londrina, v. 35, n. 2, p. 11-20, jul./dez. 2014. https://doi.org/10.5433/1679-0367.2014v35n2p11

YAMAGUCHI, M. U. et al. Qualidade microbiológica da água para consumo humano em instituição de ensino de Maringá-PR. O mundo da saúde, v. 37, n. 3, p. 312-320, abr./jun. 2013. 